\title{
Chronic Diseases in High-Cost Users of Hospital, Primary Care, and Prescription Medication in the Capital Region of Denmark
}

\author{
Cecilie Goltermann Toxvaerd, MSc ${ }^{7}$, Kirstine Skov Benthien, MSc PhD', \\ Anne Helms Andreasen, MSc ${ }^{7}$, Ann Nielsen, $M P H P h D^{7}$, Merete Osler, $M D P h D^{1,2}$, and \\ Nanna Borup Johansen, MD PhD ${ }^{7}$ \\ ${ }^{1}$ Center for Clinical Research and Prevention, Bispebjerg and Frederiksberg Hospital, Copenhagen, Denmark; ${ }^{2}$ Section for Epidemiology, \\ Department of Public Health, University of Copenhagen, Copenhagen, Denmark.
}

BACKGROUND: A small proportion of patients account for the majority of health care costs. This group is often referred to as high-cost users (HCU). A frequently described characteristic of HCU is chronic disease. Yet, there is a gap in understanding the economic burden of chronic diseases associated with HCU to different types of health care services.

OBJECTIVE: To analyze which frequent chronic diseases have the strongest association with HCU overall, and HCU in hospital, primary care, and prescription medication.

DESIGN: This is a register-based observational study on Danish health service costs for various diseases in different medical settings.

PARTICIPANTS: A total of 1,350,677 individuals aged $\geq$ 18 years living in the Capital Region of Denmark by 1 January 2012 were included.

MAIN MEASURES: Chronic diseases, costs, and sociodemographic data were extracted from the nationwide registers, including data from hospitals, primary care, and medicine consumption. These information were merged on an individual level.

KEY RESULTS: Cancer, mental disorders except depression, and heart diseases have the strongest association with HCU overall. Mental disorders except depression were in the three diseases most prevalent in HCU in all the three health care services.

CONCLUSIONS: Our results show that the chronic diseases that have the strongest association with HCU differ between different types of health care services. Our findings may be helpful in informing future policies about health care organization and may guide to different prevention, treatment, and rehabilitation strategies that could lessen the burden in the hospital.

Prior Presentations Poster at NordicEPI 2017, 13-15 September, by Nanna Borup Johansen (title: Chronic diseases and high-cost use of health care services)

Electronic supplementary material The online version of this article (https://doi.org/10.1007/s11606-019-05315-w) contains supplementary material, which is available to authorized users.

Received September 6, 2018

Accepted July 30, 2019

Published online September 11, 2019
KEY WORDS: chronic disease; cost analysis; health care costs; health services research.

J Gen Intern Med 34(11):2421-26

DOI: $10.1007 / \mathrm{s} 11606-019-05315-\mathrm{w}$

(C) Society of General Internal Medicine 2019

\section{INTRODUCTION}

Health care spending has risen significantly in the past decade in the western part of the world and is expected to be even higher in the future. ${ }^{1,2}$ Studies from the USA and Canada have shown that only $5 \%$ of the population accounts for half of total health care costs. ${ }^{1-5}$ Data from Denmark provide similar results. ${ }^{6}$ This group is often referred to as high-cost users (HCU).

The characterization of HCU has received substantial attention. ${ }^{7-10}$ Previous studies have found HCU to be older, ${ }^{8,9,11-}$ ${ }^{13}$ less educated, have low income, ${ }^{9}$ and poorer self-perceived health. ${ }^{8}$ Another frequently described characteristic of $\mathrm{HCU}$ is multimorbidity. ${ }^{8-13}$

Despite increased interest in chronic diseases, $\mathrm{HCU}$, and the conspicuous development in health care costs, knowledge about which chronic diseases are associated with HCU is very sparse. Few studies have examined the most expensive diseases overall but have been limited to the use of self-reports, private insurances, and hospital admissions. ${ }^{14-17}$

Only a few studies have examined spending across different types of health care services, but not with respect to specific chronic diseases. ${ }^{10,18}$ There is still a gap in understanding the economic burden of chronic diseases to different types of health care services to advice future health care policies and create new models of health care delivery.

The aim of this study was to examine which frequent chronic diseases have the strongest association with HCU overall, and HCU in hospital, primary care, and prescription medication, respectively, based on registry data from an unselected general population. 


\section{METHODS}

\section{Population and Study Design}

The present study is an observational study of register data from all individuals aged $\geq 18$ years old living in the Capital Region of Denmark by 1 January 2012. In Denmark, health care coverage is universal, predominantly publicly financed by taxes. All individuals registered as residents in Denmark are entitled to health care that is largely free of charge. Prescription medication is however only partially reimbursed. ${ }^{19}$ All public health care services as well as costs are registered in Danish central registers on an individual level. ${ }^{20}$ In the present study, information from several Danish registers were linked through a unique Danish person identification number (CPR number) to analyze data on an individual level. ${ }^{21}$ According to Danish legislation, register-based studies require legislation permission from the Danish Data Protection Agency (j.nr. 2012-58-0004, KPU-2012-09).

\section{Health Care Costs}

Information on costs are registered on the date of discharge from hospital, the date of visit to outpatient clinic, the week of visit to primary care, and the day of purchase of medicine in the period 1 January 2012 to 31 December 2012. Costs are presented in USD (exchange rate $1 \mathrm{USD}=5.6438 / 1 \mathrm{DKK}=0.1772 \mathrm{USD}, 31$ December 2012).

Annual Hospital Costs. Hospital annual costs included all somatic and psychiatric hospital admissions and visits in outpatient clinics that are based on specialized hospital units. Costs were calculated using the Danish tariff system of the diagnosis-related groups (DRG) and the Danish Ambulatory Grouping (DAG) defined by the Danish National Board of Health. ${ }^{22}$ The DRG and DAG charges for 2012 were used as cost estimates. Information about hospital annual costs on an individual level were retrieved from the Danish National Patient Register (DNPR). ${ }^{23,} 24$

Annual Primary Care Costs. The primary care includes general practitioners (GPs), medical specialists in private practice (primarily ophthalmologists, gynecologists, dermatologists, otorhinolaryngologists, psychiatrists), dentists, physiotherapists, occupational therapists, psychologists, podiatrists, and chiropractors. ${ }^{20}$ Data from the primary care was retrieved from the Danish National Health Service Register for Primary Care (NHSR) which contains documented information about the activities of health care professionals contracted with the tax-funded public health care system. ${ }^{20}$ For some of the services (dentists, physiotherapists, psychologists, podiatrists, and chiropractors), the costs are divided between the public health care system and the patients' self-payment. The patient's self-payment is however not available and therefore not included in this study.
Annual Prescription Medication Costs. Information on filled prescriptions was retrieved from the National Prescription Register (NPR). NPR includes drug information on dispending data, pharmacy retail price, patient copayment, and reimbursement codes. ${ }^{25}$ The retail cost at the date of purchase was used to assign annual costs of prescription drugs. Prescription medication costs were calculated as the sum of the tax-financed drug reimbursement and the citizen's own payment. Prescription medication costs in hospitals are included in hospital costs as part of the DRG charges.

Total Annual Costs. Total annual health care costs were calculated as the sum of all costs of all health care services including hospital annual costs, annual primary care costs, and annual prescription medication costs. Further details on costs are found online in Appendix 1.

\section{Definition of High-Cost Users}

HCU were defined as those who ranked in the top 5\% according to total annual costs in 2012 in hospital, primary care, and prescription medication, and overall. HCU are categorized in

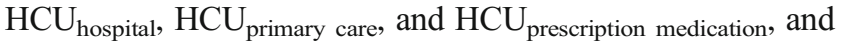
$\mathrm{HCU}_{\text {overall. }}$

\section{Measures of Chronic Disease and Multimorbidity}

Definition of chronic diseases is primarily based on relevant diagnoses from DNPR, relevant dispensing of medicine from NPR (2 dispensing within 12 months), and relevant procedures from NHSR. To define prevalence of chronic diseases on 1 January 2012, data from the three registers were used from the previous 5 years (2007-2011). Data from 2011 and 2012 were used to define incidence of disease during 2012. Eleven chronic diseases were included due to their frequency and valid register information: diabetes (types 1 and 2), heart disease, stroke, chronic obstructive pulmonary disease (COPD), asthma, cancer, inflammatory joint disease, osteoporosis, long-term depression (treatment with antidepressant medication $\geq 2$ years), mental disorders except depression (schizophrenia, schizotypal mental disorder, paranoid psychoses, acute and transient psychoses, and bipolar affective disorder), and dementia. More details of the definition of the diseases including ICD-10 codes and prescription medication are provided online in Appendix 2. Multimorbidity was categorized in one, two, and $\geq 3$ chronic diseases.

\section{Sociodemographic Factors}

Sociodemographic factors included age, sex, income, highest achieved education, ethnicity, and cohabitation status. Ethnicity was divided into three groups: Danish, other Western countries, and non-Western countries. Education was categorized into four groups: primary school and secondary school, vocational education, short- and medium-cycle higher 
education, and long-cycle higher education. Income was categorized into 6 groups, and cohabitant status was categorized as cohabitating or single. Sociodemographic factors are included as covariates in the adjusted models to focus on the diagnoses. Details on the registers are provided online in Appendix 3.

\section{Statistical Analysis}

Characteristics of the total study population, $\mathrm{HCU}_{\text {overall, }}$

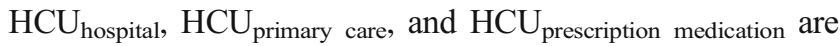
presented as numbers and percentages. By entering all 11 diseases in separate models, the effect (hazard ratio) of having the diseases is compared with not having the disease. One, two, and greater than or equal to three diseases were compared with having no disease. A sensitivity analysis was performed with all diseases in the same model. Data were analyzed by Cox regression models with time since 1 January 2012 as time scale. To define data of event, costs were accumulated on daily basis for each person during 2012 and the date of reaching the cutoff for HCU was identified and used as date of event. Observations were censured at date of death, date of migration from the Capital Region of Denmark, or 31 December 2012, whichever came first. Each of the 11 chronic diseases was entered in separate models as time-dependent variables with change in value at time of disease incidence. Analyses were performed using SAS version 9.4 (TS1M3 SAS/STAT 14.1). All processing and analyses of data were performed through a remote access to Statistics Denmark.

\section{RESULTS}

The study included $1,350,677$ individuals $\geq 18$ years old living in the Capital Region of Denmark at 1 January 2012. Out of these, a total of 67,534 were ranked in the top 5\% ( $\left.\mathrm{HCU}_{\text {overall }}\right)$ according to total annual costs in 2012 with 36,810 women and 30,724 men (Table 1). In 2012, 77\% were hospital costs $(3,612,887,668$ USD as shown in app 4); $13 \%$, primary care costs $(585,599,004$ USD as shown in app 4); and $10 \%$, prescription medication costs (480,967,464 USD) (online material: Appendix 4). The cutoffs for HCU are also provided online in Appendix 4. Total costs of the top 5\% $\left(\mathrm{HCU}_{\text {overall }}\right)$ were $2,519,655,536 \mathrm{USD}$ which corresponds to $53.8 \%$ of total annual costs.

The $\mathrm{HCU}_{\text {overall }}$ population tended to be older, of Danish ethnicity, single, having short education, and have an annual income between 17,719 and 26,578 USD (Table 1). Further description of the populations of $\mathrm{HCU}_{\text {hospital }}, \mathrm{HCU}_{\text {primary care, }}$ and $\mathrm{HCU}_{\text {prescription medication }}$ is presented online in Appendix 5.

In the unadjusted models, model 1 , the hazard ratio (HR) for $\mathrm{HCU}_{\text {overall }}$ was strongest for cancer, stroke, and heart disease (Table 2). In the fully adjusted model, model 2 , HR was attenuated (Table 2): six times as many patients with cancer were HCU (HR 6.23 (95\% CI, 6.11, 6.35)), four times as many patients with mental disorders except depression were HCU,
Table 1 Characteristics of the Study Population and Overall HighCost Users

\begin{tabular}{|c|c|c|c|c|}
\hline & \multicolumn{2}{|c|}{$\begin{array}{l}\text { Total study } \\
\text { population } \\
(n=1,350,667)\end{array}$} & \multicolumn{2}{|c|}{$\begin{array}{l}\text { Overall high- } \\
\text { cost users } \\
(n=67,534)\end{array}$} \\
\hline & $n$ & $(\%)$ & $n$ & $(\%)$ \\
\hline \multicolumn{5}{|l|}{ Sex } \\
\hline Women & 698,301 & $(51.7)$ & 36,810 & (54.5) \\
\hline Men & 652,376 & (48.3) & 30,724 & $(45.5)$ \\
\hline \multicolumn{5}{|l|}{ Age group (years) } \\
\hline $18-29$ & 277,167 & (20.5) & 4509 & (6.7) \\
\hline $30-39$ & 250,940 & (18.6) & 5674 & (8.4) \\
\hline $40-49$ & 250,760 & (18.6) & 7342 & (10.9) \\
\hline $50-59$ & 202,573 & $(15.0)$ & 9675 & (14.3) \\
\hline $60-69$ & 192,839 & (14.3) & 15,082 & (22.3) \\
\hline $70-79$ & 109,598 & $(8.1)$ & 13,840 & (20.5) \\
\hline$\geq 80$ & 66,800 & $(5.0)$ & 11,412 & (16.9) \\
\hline \multicolumn{5}{|l|}{ Ethnicity } \\
\hline Danish & $1,134,518$ & $(84.0)$ & 60,522 & (89.6) \\
\hline Other Western countries & 77,119 & $(5.7)$ & 2598 & $(3.8)$ \\
\hline Non-Western countries & 139,040 & $(10.3)$ & 4414 & (6.5) \\
\hline \multicolumn{5}{|l|}{ Cohabitation } \\
\hline Cohabitant & 789,599 & $(58.5)$ & 32,305 & $(47.8)$ \\
\hline Single & 561,078 & $(41.5)$ & 35,229 & $(52.2)$ \\
\hline \multicolumn{5}{|l|}{ Education } \\
\hline $\begin{array}{l}\text { Primary school or } \\
\text { secondary education }\end{array}$ & 453,504 & $(35.6)$ & 26,182 & $(38.8)$ \\
\hline Vocational education & 373,698 & (29.4) & 21,814 & (32.3) \\
\hline $\begin{array}{l}\text { Short- and medium-cycle } \\
\text { higher education }\end{array}$ & 281,963 & $(22.1)$ & 11,015 & (16.3) \\
\hline higher education & & & & \\
\hline Long-cycle higher & 164,108 & (12.9) & 5045 & $(7.5)$ \\
\hline \multicolumn{5}{|l|}{ Income* (USD) } \\
\hline 0 to $<17,719$ & 118,781 & $(9.1)$ & 2882 & (4.3) \\
\hline 17,719 to $<26,578$ & 185,400 & (14.1) & 15,978 & (23.7) \\
\hline 26,578 to $<44,296$ & 320,924 & (24.5) & 23,418 & (34.7) \\
\hline 44,296 to $<66,445$ & 361,826 & $(27.6)$ & 15,058 & $(22.3)$ \\
\hline 66,445 to $<93,002$ & 215,633 & (16.4) & 6601 & $(9.8)$ \\
\hline$\geq 93,002$ & 109,896 & $(8.4)$ & 3025 & (4.5) \\
\hline
\end{tabular}

and three times as many patients with heart disease were HCU compared with those without these diseases.

The sensitivity analyses, including all diseases (online material: Appendix 6), show that HR was attenuated for all diseases for $\mathrm{HCU}_{\text {overall }}$ except for long-term depression and mental disorders except depression compared with models 1 and 2 in Table 2.

$\mathrm{HR}$ for $\mathrm{HCU}_{\text {hospital }}$ differed slightly from $\mathrm{HCU}_{\text {overall }}$ (Table 3). For $\mathrm{HCU}_{\text {primary care }} \mathrm{HR}$ was strongest for mental disorders except depression with almost three times (HR 2.84 (95\% CI, 2.77, 2.92)) as many patients being HCU compared with those without this disease followed by long-term depression and stroke (Table 3). The strongest HR for $\mathrm{HCU}_{\text {prescription }}$ medication was mental disorders except depression (HR 6.13 (95\% CI, 6.00, 6.26)) with six times as many patients being HCU compared with those without this disease followed by COPD and diabetes (Table 3).

The association between number of chronic diseases and $\mathrm{HCU}$ is presented in Table 4. For $\mathrm{HCU}_{\text {overall, }}$, more than five times as many patients with one chronic disease were $\mathrm{HCU}$ (HR 5.24 (95\% CI, 5.11, 5.36)) and almost 17.5 times as many 
Table 2 Prevalence of Chronic Diseases in the Total Population and Among Overall HCU, and the Associations Between Chronic Diseases and Overall HCU

\begin{tabular}{|c|c|c|c|c|c|c|c|c|}
\hline & \multicolumn{2}{|c|}{$\begin{array}{l}\text { Total population } \\
(n=1,350,677)\end{array}$} & \multicolumn{2}{|c|}{$\begin{array}{l}\text { Overall high-cost } \\
\text { users }(n=67,534)\end{array}$} & \multicolumn{4}{|c|}{ Overall high-cost users } \\
\hline & \multirow[t]{2}{*}{$n$} & \multirow[t]{2}{*}{$(\%)$} & \multirow[t]{2}{*}{$n$} & \multirow[t]{2}{*}{$(\%)$} & \multicolumn{2}{|c|}{ Model 1} & \multicolumn{2}{|c|}{ Model 2} \\
\hline & & & & & HR & HR (95\% CI) & HR & HR $(95 \%$ CI $)$ \\
\hline Diabetes & 62,891 & $(4.7)$ & 9708 & $(14.4)$ & 3.69 & $(3.62,3.77)$ & 2.00 & $(1.96,2.05)$ \\
\hline Heart disease & 59,606 & $(4.4)$ & 12,107 & (17.9) & 6.54 & $(6.42,6.66)$ & 3.12 & $(3.06,3.18)$ \\
\hline Stroke & 27,916 & $(2.1)$ & 5601 & $(8.3)$ & 6.69 & $(6.53,6.85)$ & 3.08 & $(3.00,3.15)$ \\
\hline COPD* & 38,346 & $(4.0)$ & 8343 & (12.4) & 5.07 & $(4.97,5.18)$ & 3.04 & $(2.97,3.11)$ \\
\hline Asthma & 68,049 & $(5.0)$ & 4721 & $(7.0)$ & 1.41 & $(1.37,1.45)$ & 1.38 & $(1.34,1.42)$ \\
\hline Cancer & 44,082 & $(3.3)$ & 10,903 & (16.1) & 10.48 & $(10.30,10.67)$ & 6.23 & $(6.11,6.35)$ \\
\hline Inflammatory joint diseases & 32,464 & $(2.4)$ & 6367 & $(9.4)$ & 4.59 & $(4.47,4.71)$ & 2.69 & $(2.62,2.76)$ \\
\hline Osteoporosis & 34,644 & $(2.6)$ & 6060 & $(9.0)$ & 4.10 & $(3.99,4.20)$ & 1.94 & $(1.88,1.99)$ \\
\hline Long-term depression & 67,277 & $(5.0)$ & 7759 & $(11.5)$ & 2.51 & $(2.45,2.57)$ & 1.85 & $(1.81,1.89)$ \\
\hline Mental disorders except depression & 38,501 & $(2.9)$ & 8774 & $(13.0)$ & 5.83 & $(5.70,5.96)$ & 4.28 & $(4.18,4.38)$ \\
\hline Dementia* & 10,191 & $(3.7)$ & 1778 & $(2.6)$ & 2.13 & $(2.04,2.22)$ & 1.62 & $(1.54,1.69)$ \\
\hline
\end{tabular}

Individuals may appear in more than one disease group

*COPD variable only includes individuals $\geq 35$ years. Dementia variable only includes individuals $\geq 65$ years

Model 1, unadjusted; model 2, adjusted for sex, age, ethnicity, education, income, and cohabitant status

HR hazard ratio, CI confidence interval, $n$ number

patients with three or more chronic diseases were HCU (HR 17.58 (95\% CI, 17.00, 18.18)) compared with those with no

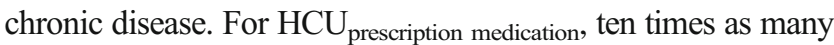
patients with one chronic disease were HCU (HR 10.03 (95\% CI, 9.77, 10.29) and more than 45 times as many patients with three or more chronic diseases were HCU (44.23 (95\% CI, $44.23,47.23)$ compared with those with no chronic disease.

\section{DISCUSSION}

To our knowledge, this is the first study to examine $\mathrm{HCU}$ among patients with chronic diseases across different types of health care services in an unselected general population based on registry data. In this large population-based study of more than 1.3 million individuals, we have examined the association between 11 frequent chronic diseases and their association with HCU. In the fully adjusted analysis, we found that for $\mathrm{HCU}_{\text {overall }}$, six times as many patients with cancer were $\mathrm{HCU}$, four times as many patients with mental disorders except depression were HCU, and three times as many patients with heart disease were HCU compared with those without these diseases. Several studies have examined the characteristics of $\mathrm{HCU}$, showing that $\mathrm{HCU}$ are characterized by the presence of multiple chronic diseases. ${ }^{8-13}$ Despite this strong association, studies examining specific chronic diseases associated with HCU are very sparse. ${ }^{1,11,17}$ One study from 2015 , based on The Medical Expenditures Panel Survey which provides a representative estimate of health care use and costs for the US civilian non-institutionalized population, did find the most costly diseases to be cancer, mental disorders, heart diseases, and arthritis, and other non-traumatic disorders ${ }^{17}$ which is in line with our results. An explanation for cancer to be highly associated with HCU may be due to very high and rising expenses for cancer drugs. ${ }^{26}$ The high costs incurred by patients with cancer may also stem from the increasing number of available and expensive treatments even with disease progression. Specialized palliative care may support a timely cessation of chemotherapy at the end of life as demonstrated in observation and experimental studies. ${ }^{27,28}$

Only two studies have examined spending by types of health care services, ${ }^{10,18}$ but not specified on chronic diseases. Furthermore, none of these studies ${ }^{10,18}$ have results on the primary care. In 2011, Conway and colleagues found that the

Table 3 Associations Between Chronic Diseases and HCU in Hospital, Primary Care, and Prescription Medication

\begin{tabular}{|c|c|c|c|c|c|c|}
\hline \multirow{3}{*}{$\begin{array}{l}\begin{array}{l}\text { Chronic } \\
\text { disease }\end{array} \\
\text { Diabetes }\end{array}$} & \multicolumn{6}{|c|}{ High-cost users, HR (95\% CI) } \\
\hline & \multicolumn{2}{|c|}{$\mathbf{H C} \mathbf{U}_{\text {hospital }}$} & \multicolumn{2}{|c|}{$\begin{array}{l}\mathbf{H C} \mathbf{U}_{\text {primary }} \\
\text { care }\end{array}$} & \multicolumn{2}{|c|}{$\begin{array}{l}\mathrm{HCU}_{\text {prescription }} \\
\text { medication }\end{array}$} \\
\hline & 1.83 & $\begin{array}{l}(1.79 \\
1.87)\end{array}$ & 1.90 & $\begin{array}{l}(1.85, \\
1.95)\end{array}$ & 4.93 & $\begin{array}{l}(4.84, \\
5.02)\end{array}$ \\
\hline Heart disease & 2.97 & $\begin{array}{l}(2.91, \\
3.03)\end{array}$ & 2.00 & $\begin{array}{l}(1.95 \\
2.05)\end{array}$ & 3.00 & $\begin{array}{l}(2.93 \\
3.06)\end{array}$ \\
\hline Stroke & 2.97 & $\begin{array}{l}(2.90 \\
3.05)\end{array}$ & 2.20 & $\begin{array}{l}(2.13 \\
2.27)\end{array}$ & 2.04 & $\begin{array}{l}(1.99 \\
2.10)\end{array}$ \\
\hline COPD & 2.81 & $\begin{array}{l}(2.75 \\
2.87)\end{array}$ & 1.74 & $\begin{array}{l}(1.69 \\
1.79)\end{array}$ & 5.33 & $\begin{array}{l}(5.23 \\
5.43)\end{array}$ \\
\hline Asthma & 1.30 & $\begin{array}{l}(1.26, \\
1.34)\end{array}$ & 1.80 & $\begin{array}{l}(1.75, \\
1.84)\end{array}$ & 2.94 & $\begin{array}{l}(2.88 \\
3.01)\end{array}$ \\
\hline Cancer & 6.36 & $\begin{array}{l}(6.24 \\
6.48)\end{array}$ & 1.24 & $\begin{array}{l}(1.20 \\
1.28)\end{array}$ & 1.44 & $\begin{array}{l}(1.41, \\
1.49)\end{array}$ \\
\hline $\begin{array}{l}\text { Inflammatory } \\
\text { joint diseases }\end{array}$ & 2.62 & $\begin{array}{l}(2.55 \\
2.69)\end{array}$ & 2.19 & $\begin{array}{l}(2.12 \\
2.25)\end{array}$ & 1.94 & $\begin{array}{l}(1.88, \\
1.99)\end{array}$ \\
\hline Osteoporosis & 1.81 & $\begin{array}{l}(1.76, \\
1.86)\end{array}$ & 1.60 & $\begin{array}{l}(1.55, \\
1.65)\end{array}$ & 2.11 & $\begin{array}{l}(2.05 \\
2.17)\end{array}$ \\
\hline $\begin{array}{l}\text { Long-term } \\
\text { depression }\end{array}$ & 1.73 & $\begin{array}{l}(1.69 \\
1.77)\end{array}$ & 2.55 & $\begin{array}{l}(2.50 \\
2.61)\end{array}$ & 2.63 & $\begin{array}{l}(2.57 \\
2.68)\end{array}$ \\
\hline $\begin{array}{l}\text { Mental } \\
\text { disorders } \\
\text { except } \\
\text { depression }\end{array}$ & 3.91 & $\begin{array}{l}(3.81, \\
4.00)\end{array}$ & 2.84 & $\begin{array}{l}(2.77 \\
2.92)\end{array}$ & 6.13 & $\begin{array}{l}(6.00 \\
6.26)\end{array}$ \\
\hline Dementia & 1.48 & $\begin{array}{l}(1.41, \\
1.55)\end{array}$ & 1.09 & $\begin{array}{l}(1.02, \\
1.16)\end{array}$ & 4.09 & $\begin{array}{l}(3.94 \\
4.23)\end{array}$ \\
\hline
\end{tabular}

Analyses are adjusted for sex, age, ethnicity, education, income, and cohabitant status. Individuals may appear in more than one disease group

HR hazard ratio, CI confidence interval 
Table 4 Multimorbidity

\begin{tabular}{|c|c|c|c|c|c|c|c|c|}
\hline \multicolumn{9}{|c|}{ High-cost users, HR (95\% CI) } \\
\hline \multirow{2}{*}{$\begin{array}{l}\text { Multimorbidity } \\
1 \text { chronic disease }\end{array}$} & \multicolumn{2}{|c|}{$\mathbf{H C} \mathbf{U}_{\text {overall }}$} & \multicolumn{2}{|c|}{$\mathbf{H C U}_{\text {hospital }}$} & \multicolumn{2}{|c|}{$H_{C} U_{\text {primary care }}$} & \multicolumn{2}{|c|}{$H C U_{\text {prescription medication }}$} \\
\hline & 5.24 & $(5.11,5.36)$ & 4.61 & $(4.51,4.72)$ & 2.43 & $(2.38,2.48)$ & 10.03 & $(9.77,10.29)$ \\
\hline 2 chronic diseases & 9.76 & $(9.48,10.06)$ & 8.01 & $(7.78,8.24)$ & 3.81 & $(3.72,3.92)$ & 24.74 & $(24.03,25.48)$ \\
\hline$\geq 3$ chronic diseases & 17.58 & $(17.00,18.18)$ & 13.51 & $(13.06,13.97)$ & 5.23 & $(5.06,5.41)$ & 45.71 & $(44.23,47.23)$ \\
\hline
\end{tabular}

Analyses are adjusted for sex, age, ethnicity, education, income, and cohabitant status

HR hazard ratio, CI confidence interval

majority (47\%) of health care spending was related to chronic diseases of where $29.9 \%$ was attributable to inpatient and $34.8 \%$ to prescription medicine. ${ }^{18}$ We found that chronic diseases having the strongest association with $\mathrm{HCU}_{\text {hospital }}$ were similar to $\mathrm{HCU}_{\text {overall. }}$ Since most health care costs are hospital costs, this may explain why $\mathrm{HCU}_{\text {overall }}$ and $\mathrm{HCU}_{\text {hospital }}$ are similar. Hayes et al. showed that HCU were more than three times more likely to be hospitalized compared with non-HCU, ${ }^{9}$ while Joynt et al. found that HCU accounted for $79 \%$ of inpatient costs. ${ }^{11}$ Our results along with these studies ${ }^{9,} 11$ demonstrate that HCU represent a major burden in the hospital. A reason why almost four times as many patients with mental disorders except depression were $\mathrm{HCU}_{\text {hospital }}$ may be that patients with mental disorders have been reported to be at increased risk of somatic comorbidity ${ }^{29}$ and higher risk of hospitalization. ${ }^{30}$

Chronic diseases associated with $\mathrm{HCU}_{\text {primary care }}$ differed from those associated with $\mathrm{HCU}_{\text {hospital }}$. The strongest association between chronic diseases and $\mathrm{HCU}_{\text {primary care was found for mental }}$ disorders except depression with almost three times as many patients being HCU compared with those without this disease followed by long-term depression. A reason that both mental disorders except depression and long-term depression have a very strong association with $\mathrm{HCU}_{\text {primary care }}$ may be caused by a political decision of prioritizing psychiatric treatment in the primary care. Our results showed that the association between

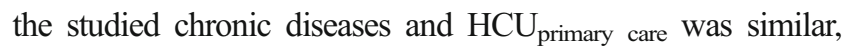
likely because all chronic diseases are partially managed in primary care with similar time slots across diagnoses and therefore have a corresponding consumption of resources.

Chronic diseases associated with $\mathrm{HCU}_{\text {prescription medication }}$ also

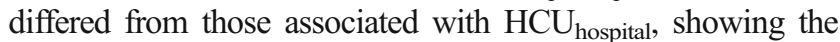
strongest association between mental disorders except depression and $\mathrm{HCU}_{\text {prescription medication }}$ with six times as many patients being HCU compared with those without this disease. COPD and diabetes did also have a strong association with

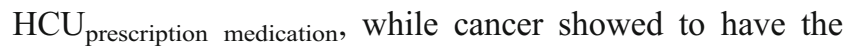

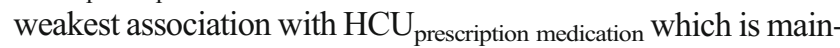
ly because antineoplastic treatment is provided by hospitals.

One, two, three, and more chronic diseases were compared with individuals with none of the studied chronic diseases. This is reflected by a strong association between any chronic disease and HCU in all three health care services that gets stronger with the addition of more chronic diseases. For $\mathrm{HCU}_{\text {prescription medication, }} 46$ times as many patients with three or more chronic diseases were HCU. This demonstrates the economic burden associated with long-term pharmaceutical treatment of chronic diseases. This finding is supported by the aforementioned study by Conway et al. ${ }^{18}$ In Denmark, patients' annual spending on prescription medication is covered by the state if it exceeds 620 USD.

This study has several strengths. All adults in the Capital Region of Denmark were included in this study. Hence, the study population comprises one-third of the Danish adult population which too has the same life expectancy as the adult population in the rest of the country. ${ }^{31}$ Therefore, our population is highly comparable with the Danish population. By using register data, we were able to avoid recall bias on chronic diseases, hospital admissions, disease control in outpatient clinics and GPs, and prescription medication purchases. We have included all costs for each patient and not disease-related costs only. However, except for prescription medication, we did not have any information on the patient's self-payment. By defining diseases primarily through hospital diagnoses and prescription medication purchases, and not on diagnoses in general practice, we may have underestimated the prevalence of diseases primarily controlled by GPs and consequently also their costs in primary care. As such, asthma which is primarily treated by GPs is not strongly associated

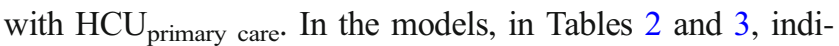
viduals may appear in more than one disease group. To adjust for this, we made an additional sensitivity analysis (online material: Appendix 6) which showed that the association between chronic diseases and $\mathrm{HCU}_{\text {overall }}$ attenuated for most diseases compared with the associations in Tables 2 and 3.

In conclusion, we found that cancer, mental disorders except depression, and heart disease had the strongest association with $\mathrm{HCU}_{\text {overall. }}$ Cancer also had the strongest association with $\mathrm{HCU}_{\text {hospital }}$ while mental disorders except depression were in the three diseases most prevalent in HCU in all three health care services. For $\mathrm{HCU}_{\text {prescription medication, mental dis- }}$ orders except depression had the strongest association with HCU. Our results show that frequent chronic diseases associated with HCU differ between types of health care services. There may be clinical indications for this such as cancer treatment mainly taking place in hospitals, and political priorities may also allocate resources to particular types of health care services for some diseases. Knowledge of this study may be helpful to inform future policies about health care organization and guide to different prevention, treatment, and 
rehabilitation strategies that could lessen the burden in the hospital. If more resources in the health care sector are moved from the hospital to the primary care, it might be possible to treat more patients in the primary care where the costs of treatment are lower. However, this does only include diseases that can be handled in the primary care and does not include for instance cancer. The results of this study call for further research into the dynamics of individuals becoming HCU and the relationship with chronic diseases.

Corresponding Author: Cecilie Goltermann Toxværd, MSc; Center for Clinical Research and PreventionBispebjerg and Frederiksberg Hospital, Copenhagen, Denmark (e-mail: cecilie.goltermann. toxvaerd@regionh.dk).

Funding Information This project was funded by the Capital Region of Denmark.

\section{Compliance with Ethical Standards:}

Conflict of Interest: The authors declare that they do not have a conflict of interest.

Prior Presentations: Poster at NordicEPI 2017, 13-15 September, by Nanna Borup Johansen (title: Chronic diseases and high-cost use of health care services).

\section{REFERENCES}

1. Pritchard D, Petrilla A, Hallinan S, Taylor DH, Jr., Schabert VF, Dubois RW. What Contributes Most to High Health Care Costs? Health Care Spending in High Resource Patients. J Manag Care Spec Pharm 2016;22(2):102-9.

2. Ronksley PE, McKay JA, Kobewka DM, Mulpuru S, Forster AJ. Patterns of health care use in a high-cost inpatient population in Ottawa, Ontario: a retrospective observational study. CMAJ Open 2015;3(1):E111-8.

3. Stanton M, Rutherford M. The High Concentration of U.S. Health Care Expenditures. Res Action 2006;19:1-11.

4. Cohen SB, Yu W. The Concentration and Persistence in the Level of Health Expenditures over Time: Estimates for the U.S. Population, 20082009. Agency for Healthcare Research and Quality - Medical Expenditure Panel Survey. 2012;STATISTICAL BRIEF \#354. https://meps.ahrq.gov/ data files/publications/st354/stat354.pdf. Accessed 03.09.19

5. Riley GF. Long-term trends in the concentration of Medicare spending. Health Aff 2007;26(3):808-16.

6. Lau C, Lykke M, Andreasen A, Bekker-Jeppesen M, Buhelt L, Robinson K, et al. Health Profile 2013 - Chronic Disease. The Capital Region of Denmarht. Research Center for Prevention and Health. 2015. https: / /www.frederiksberghospital.dk/ckff/sektioner/SSF / sundhedsprofilen / Documents / Sundhedsprofil\%202013/ Sundhedsprofil\%202013\%20-\%20Kronisk\%20sygdom.pdf. Accessed 03.09.19

7. Fitzpatrick T, Rosella LC, Calzavara A, Petch J, Pinto AD, Manson H, et al. Looking Beyond Income and Education: Socioeconomic Status Gradients Among Future High-Cost Users of Health Care. Am J Prev Med 2015;49(2): 161-71.

8. Rosella LC, Fitzpatrick T, Wodchis WP, Calzavara A, Manson H, Goel V. High-cost health care users in Ontario, Canada: demographic, socioeconomic, and health status characteristics. BMC Health Serv Res $2014 ; 14: 532$.

9. Hayes SL, Salzberg CA, McCarthy D, Radley DC, Abrams MK, Shah T, et al. High-Need, High-Cost Patients: Who Are They and How Do They Use Health Care?. Issue Brief 2016;26:1-14.
10. Guilcher SJ, Bronskill SE, Guan J, Wodchis WP. Who Are the High-Cost Users? A Method for Person-Centred Attribution of Health Care Spending. PLoS One 2016;11(3):e0149179.

11. Joynt KE, Gawande AA, Orav EJ, Jha AK. Contribution of preventable acute care spending to total spending for high-cost Medicare patients. JAMA. 2013;309(24):2572-8.

12. Rashidi B, Kobewka DM, Campbell DJT, Forster AJ, Ronksley PE. Clinical factors contributing to high cost hospitalizations in a Canadian tertiary care centre. BMC Health Serv Res 2017;17(1):777.

13. Ronksley PE, Kobewka DM, McKay JA, Rothwell DM, Mulpuru S, Forster AJ. Clinical characteristics and preventable acute care spending among a high cost inpatient population. BMC Health Serv Res 2016; 16:165.

14. Druss BG, Marcus SC, Olfson M, Pincus HA. The most expensive medical conditions in America. Health Aff 2002;21(4):105-11.

15. Cohen JW, Krauss NA. Spending and service use among people with the fifteen most costly medical conditions, 1997. Health Aff 2003;22(2):12938.

16. Olin GL, Rhoades JA. The Five Most Costly Medical Conditions, 1997 and 2002: Estimates for the U.S. Civilian Noninstitutionalized Population. Agency for Healthcare Research and Quality - Medical Expenditure Panel Survey. 2005;STATISTICAL BRIEF \#80. https://meps.ahrq.gov/ data_files/publications/st80/stat80.pdf. Accessed 03.09.19

17. Soni A. Top Five Most Costly Conditions among Adults Age 18 and Older, 2012: Estimates for the U.S. Civilian Noninstitutionalized Population. Agency for Healthcare Research and Quality - Medical Expenditure Panel Survey. 2015;STATISTICAL BRIEF \#471. https://meps.ahrq.gov/data_ files/publications/st471/stat471.pdf. Accessed 03.09.19

18. Conway P, Goodrich K, Machlin S, Sasse B, Cohen J. Patient-centered care categorization of U.S. health care expenditures. Health Serv Res 2011;46(2):479-90.

19. Vrangbæk K. The health system in Denmark. Eurohealth. 2008;14 No 1.

20. Andersen JS, Folivarus ND, Krasnik A. The Danish National Health Service Register. Scand J Public Health 2011;39(Suppl 7): 34-37.

21. Pedersen CB. The Danish Civil Registration System. Scand J Public Health 2011;39(7 Suppl):22-5.

22. Ankjaer-Jensen A, Rosling $\mathbf{P}$, Bilde $\mathbf{L}$. Variable prospective financing in the Danish hospital sector and the development of a Danish case-mix system. Health Care Manag Sci 2006;(9)(3):259-68.

23. Lynge E, Sandegaard JL, Rebolj M. The Danish National Patient Register. Scand J Public Health 2011;39(7 Suppl):30-3.

24. Schmidt M, Schmidt SA, Sandegaard JL, Ehrenstein V, Pedersen L, Sorensen HT. The Danish National Patient Registry: a review of content, data quality, and research potential. Clin Epidemiol 2015;7:449-90.

25. Kildemoes HW, Sorensen HT, Hallas J. The Danish National Prescription Registry. Scand J Public Health 2011;39(7 Suppl):38-41.

26. Kantarjian H, Rajkumar SV. Why are cancer drugs so expensive in the United States, and what are the solutions? Mayo Clin Proc 2015;90(4):500-4.

27. Skov Benthien K, Adsersen M, Petersen MA, Soelberg Vadstrup E, Sjogren P, Groenvold M. Is specialized palliative cancer care associated with use of antineoplastic treatment at the end of life? A population-based cohort study. Palliat Med 2018;32(9):1509-17. doi:https://doi.org/10. $1177 / 0269216318786393$

28. Greer JA, Pirl WF, Jackson VA, Muzikansky A, Lennes IT, Heist RS, et al. Effect of early palliative care on chemotherapy use and end-of-life care in patients with metastatic non-small-cell lung cancer. J Clin Oncol 2012;30(4):394-400. doi:https://doi.org/10.1200/jco.2011.35.7996

29. Sprah L, Dernovsek MZ, Wahlbeck K, Haaramo P. Psychiatric readmissions and their association with physical comorbidity: a systematic literature review. BMC Psychiatry 2017;17(1):2.

30. Prina AM, Cosco TD, Dening T, Beekman A, Brayne C, Huisman M. The association between depressive symptoms in the community, nonpsychiatric hospital admission and hospital outcomes: a systematic review. J Psychosom Res 2015;78(1):25-33.

31. Statistics Denmark. Lifeexpectency across part of the country. 2018. Available at: https://www.dst.dk/da/Statistik/nyt/NytHtml?cid=26702. Accessed 08-07 2019.

Publisher's Note Springer Nature remains neutral with regard to jurisdictional claims in published maps and institutional affiliations. 